\title{
DIATOMEAS COMO INDICADORAS PALEOAMBIENTALES EN LA FORMACIÓN RÍO NEGRO, PROVINCIA DE RÍO NEGRO, ARGENTINA
}

\author{
NATALIA CABALLERO \\ Departamento de Geología, Universidad Nacional del Sur, San Juan 670, Bahía Blanca 8000, Argentina. \\ natalia.caballero@uns.edu.ar
}

YESICA NASS

Departamento de Biología, Bioquímica y Farmacia, Universidad Nacional del Sur, San Juan 670, Bahía Blanca 8000, Argentina.yesi_mn@yahoo.com

\author{
BEATRIZ GUTIÉRREZ TÉLLEZ \\ Departamento de Geología, Universidad Nacional del Sur, San Juan 670, Bahía Blanca 8000, Argentina. \\ bgutierr@uns.edu.ar
}

\begin{abstract}
DIATOMS AS PALEOENVIRONMENTAL INDICATORS IN RIO NEGRO FORMATION, RIO NEGRO PROVINCE, ARGENTINA. Diatom assemblages taken from outcropping sequences located on the cliffs of the Río Negro Formation, northeast of Río Negro province were studied. Paleoenvironmental interpretations of the area, during late Mioceneearly Pliocene, were performed. Diatom data were analyzed according to ecological tolerances of the taxa. Samples from minor sedimentary sections showed a paleoenvironment composed by aeolian levels with shallow interdune lagoons, with little water flow and high influence of aridness and evaporation. The diatomological flora was represented by fresh, brackish and sea water taxa. The lagoons were characterized by being shallow interdune, with an alternation between wet and dry conditions. During wet conditions, freshwater lagoons may have established by a higher water input from the combination of different processes such meteoric water increased and phreatic level rise. In dry periods, lagoons have modified their salinity from freshwater to brackish water due to increased evaporation because of aridity. An increase in the deposition of sandy sediments, the effect of wind and the reduction of the water would have concluded with the development of these two paleoenvironments. Besides, an episodic and marginal marine influence was inferred, due to the presence of allochthonous diatoms of marine origin.
\end{abstract}

Key words: diatoms, paleoenvironments, Río Negro Formation, Río Negro province, Miocene-Pliocene, Argentine.

RESUMO - Associações de diatomáceas foram estudadas em sedimentos extraídos de sequencias aflorantes nas falésias da Formação Rio Negro, ao noroeste da província de Rio Negro. Foram realizadas interpretações paleoambientais da área no intervalo correspondente ao Neomioceno-Eoplioceno. Os dados obtidos das amostras estudadas foram analisados levando em consideração as características ecológicas de cada táxon. As seções sedimentares menores mostraram um paleoambiente composto por níveis eólicos com lagoas interdunares, com pouco fluxo de água e alta influência de aridez e evaporação. A flora de diatomácea é representada por táxons de água doce, salobra e marinha. As lagunas se caracterizaram por ser de interduna com uma alternância entre condições úmidas e secas. Durante as condições úmidas se estabeleceram lagoas com maior entrada de água, devido a combinação de diferentes processos, tais como aumento de água meteórica e aumento do nível freático. Em períodos secos, as lagoas modificaram sua salinidade de água doce à água salgada devido aumento da evaporação causada pela aridez. Um incremento na deposição de sedimentos arenosos, o efeito do vento e a redução da água finalizaram o desenvolvimento desses paleoambientes. Além disso, se estabeleceu uma influência marinha episódica e marginal devido a presença de diatomáceas alóctones de origem marinha.

Palavras-chave: diatomáceas, paleoambientes, Formação Rio Negro, Província Rio Negro, Mioceno-Plioceno, Argentina.

\section{INTRODUCCIÓN}

Las diatomeas (Clase Bacillariophyceae), son muy utilizadas como indicadores ambientales, debido a su amplia distribución geográfica, su elevado número de especies, su habilidad para colonizar diferentes medios y su capacidad de respuesta a cambios en su entorno. Son una valiosa herramienta para realizar inferencias paleoclimáticas debido a su sensibilidad a variables indicadoras de cambios ambientales, como por ejemplo profundidad del agua, temperatura, salinidad y $\mathrm{pH}$ (Round et al., 1990). Las interpretaciones de los ensambles diatomológicos, constituyen un método de aproximación en la definición de paleoambientes, ya que reflejan las condiciones físico-químicas de los ambientes 
del pasado (Gutiérrez Téllez, 2007). La reconstrucción paleoambiental a partir de estos ensambles depende de las características autoecológicas de los taxones involucrados y de su sensibilidad frente a distintas variables físico-químicas (Fayó \& Espinosa, 2014). Por otra parte, la presencia de cistos de crisostomatáceas (Clase Chrysophyceae) en los sedimentos estudiados es indicadora de cambios en el nivel de agua, salinidad y estado trófico. Sin embargo, un porcentaje alto de cistos indicaría agua pobre en nutrientes debido a que las crisostomatáceas tienden a ser competitivas bajo éstas condiciones (Smol, 1985).

El presente trabajo se focaliza en los afloramientos de la Formación Río Negro, expuestos en el sector costero de la provincia de Río Negro (Andreis, 1965), en inmediaciones de la localidad de Playa Bonita (Figura 1). Esta unidad está compuesta por depósitos acumulados en dos paleoambientes principales, uno de carácter continental (eólico) y otro marino, correspondiente a un importante evento transgresivo ("mar entrerriense") que cubrió gran parte de la costa atlántica de Argentina, el litoral sur de Uruguay y la costa sur de Brasil, durante el Mioceno tardío-Plioceno temprano (Marengo, 2000 y Sprechmann et al., 2000). Dicha transgresión es reconocida en Uruguay en los depósitos de la Formación Camacho (Goso \& Bossi, 1966), Ojeda (1982) y Dias et al. (1994) la correlacionaron con depósitos del subsuelo de la Cuenca Pelotas en Brasil. Del Río \& Martínez (1998) establecieron una correlación con depósitos argentinos, conocidos como formaciones Paraná y Puerto Madryn. Sprechmann et al. (1994) analizaron la paleoecología y sedimentología de la Formación Camacho en el Departamento de Colonia, también se observaron microfósiles de ambientes marinos, como foraminíferos y ostrácodos pero solo Sprechmann (2000) menciona diatomeas estudiadas por Martínez Macchiavello (1975), quien presenta una lista de siete taxones de ambientes salobre-marinos, siendo éste el único antecedente de estudios diatomológicos encontrados en la zona.

Las investigaciones paleodiatomológicas en el ambiente costero de la provincia de Río Negro, Argentina, reconocen trabajos como los de Wichmann $(1918,1919)$, quien señaló por primera vez la presencia de diatomeas en el área y de Frenguelli (1939a,b) quien realizó estudios sobre diatomeas, describiendo asociaciones marinas en los golfos de San Matías (provincia de Río Negro) y San Jorge (provincia de Chubut). Estudios de diatomitas de yacimientos de la zona fueron efectuados por Malumián et al. (1984). Sepúlveda y Martinez Macchiavello (1985) realizaron un trabajo paleoecológico basado en diatomeas de la zona del Bajo del Gualicho, de edad Mioceno tardío-Plioceno temprano. Escandell et al. (2009) estudió los ensambles de diatomeas de un testigo sedimentario ubicado en la desembocadura del Río Negro, con el fin de reconstruir las variaciones de salinidad y profundidad.

Doménech \& Farinati (2007) y Farinati et al. (2010) realizaron análisis tafonómicos sobre concentraciones de ostras [Crassostrea patagonica (D'Orbigny)]. Los estudios de paleoambientes lacustres en el litoral marino rionegrense son escasos pudiéndose mencionar a Angulo \& Casamiquela (1982), Zavala \& Freije (2001, 2005), Aramayo (1987, 1999, 2007, 2008), Aramayo et al. (2004) y Schillizzi \& Luna (2008). Zavala \& Freije $(2000,2001)$ y Zavala et al. (2000) realizaron estudios en la estratigrafía y sedimentología de la Formación Río Negro, los que permitieron reinterpretar gran parte de su origen.

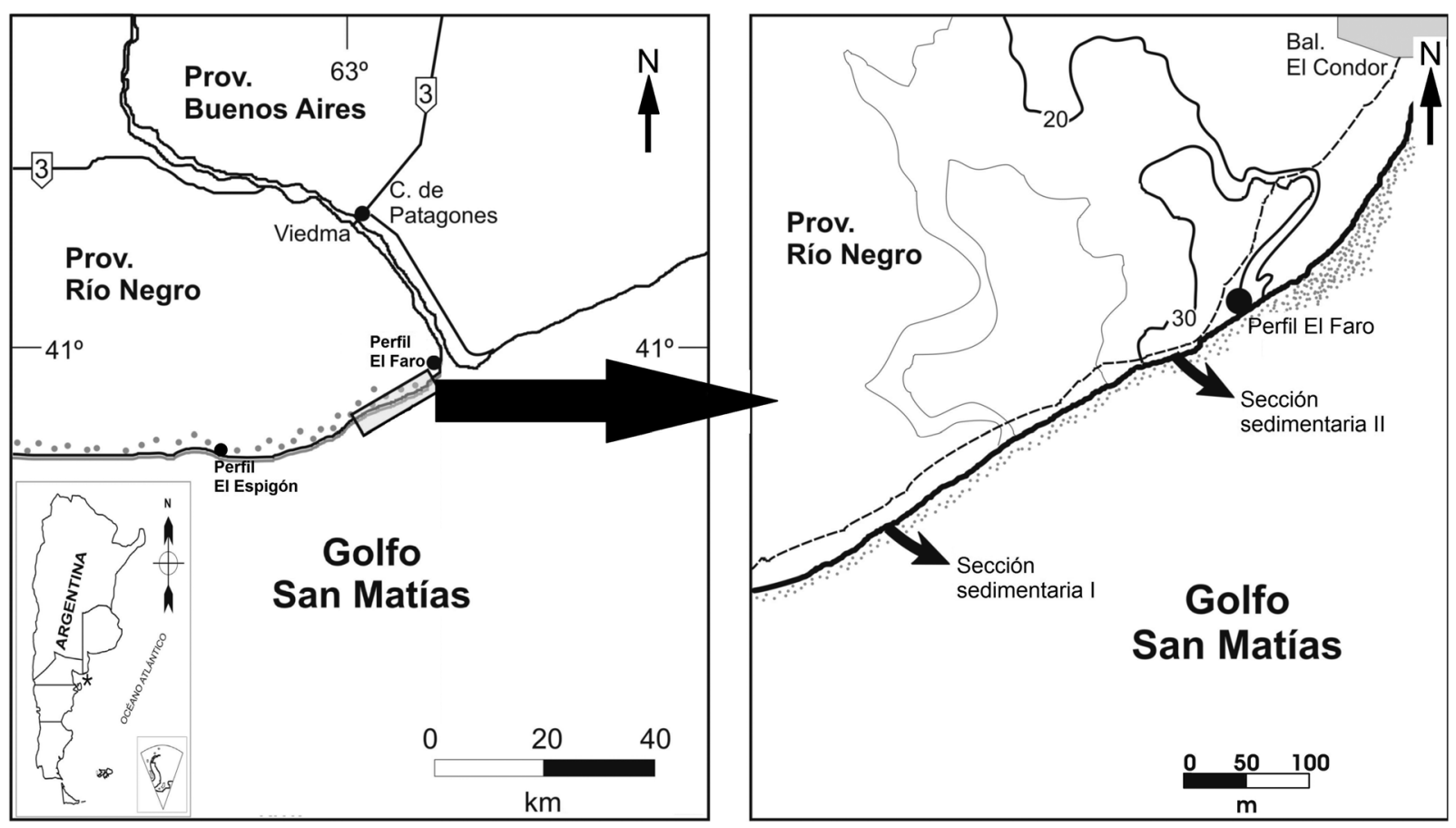

Figura 1. Ubicación geográfica de las áreas de estudio.

Figure 1. Location map of the study areas. 
El objetivo del presente trabajo es caracterizar paleoambientes, a través de la utilización de diatomeas y otros proxies, en una secuencia de perfiles aflorantes en barrancas de la Formación Río Negro, depositadas durante el Mioceno tardío-Plioceno temprano.

\section{AREA DE ESTUDIO}

La zona de estudio corresponde a la unidad geológica conocida como Formación Río Negro, de edad Mioceno tardío-Plioceno temprano, ampliamente distribuida en la costa del Océano Atlántico. Por encima de la unidad estudiada se encuentran sedimentitas fluviales denominadas "Rodados Patagónicos" asignados al Plioceno-Pleistoceno. Según Zavala \& Freije $(2000,2001)$ la Formación Río Negro, con espesor máximo de 65 metros, puede dividirse en tres unidades denominadas Miembro Inferior, Medio y Superior limitadas por discordancias. El primero, con un espesor de aproximadamente $4 \mathrm{~m}$, se compone de areniscas con estratificación cruzada, mayormente de origen eólico, depositadas en un campo de dunas separadas por áreas llanas y secas o húmedas. El Miembro Medio, de origen marino, está formado por areniscas finas bioclásticas y pelitas, con abundantes restos fósiles y espesores de hasta $10 \mathrm{~m}$. El Miembro Superior, cuya potencia máxima es de $50 \mathrm{~m}$, está principalmente constituído por sedimentitas arenosas de origen eólico y fluvial, con niveles pelíticos, tobáceos y paleosuelos (Zavala \& Freije, 2001; Perez et al., 2013). Tanto en el Miembro Superior como en el Miembro Inferior se reconocen paleoambientes lacustres (Schillizzi \& Luna, 2008). El área de estudio está ubicada en el noreste de la provincia de Río Negro, entre el Balneario El Cóndor y Playa Bonita, desde los 41 03'56'S y 62 50 '34'. O correspondientes al perfil denominado "El Faro" hasta los $41^{\circ} 07^{\prime} 11,6$ "S y $63^{\circ}$
00'34,3"O de la columna llamada "El Espigón" (Figuras 2A,B, 3A,B). También se analizaron secciones sedimentarias (SS) discontinuas (Figuras 4 A-C, 5A,B), de escasa extensión, ubicadas a unos $300 \mathrm{~m}$ en dirección SO, del perfil El Faro.

\section{MATERIAL Y MÉTODOS}

De los perfiles (El Faro y El Espigón) y las secciones sedimentarias (I y II) se obtuvieron 18 y 13 muestras, respectivamente. Las técnicas para el tratamiento químico de las muestras se realizaron siguiendo a Setty (1966) y Battarbee (1986). Se extrajeron aproximadamente $50 \mathrm{~g}$ de material en cada cambio litológico, se tomó el color en seco de cada muestra (Rock-Color-Chart, 1980) y se ingresaron al laboratorio de Paleontología Estratigráfica de la Universidad Nacional del Sur con el número de repositorio Mi.Diat.UNS número 388 al 395,400 al 409 y 424 al 436 . Los sedimentos fueron colocados en estufa a $60^{\circ} \mathrm{C}$ durante 24 horas, de cada muestra secada se pesaron $3 \mathrm{~g}$, se trataron con peróxido de hidrógeno $\left(\mathrm{H}_{2} \mathrm{O}_{2}\right)$ al $30 \%$ y ácido clorhídrico al 10\%, para eliminar la materia orgánica, las sales de calcio y carbonatos presentes. Con posterioridad, se lavaron con agua destilada hasta lograr un $\mathrm{pH}$ neutro. Con el sobrenadante obtenido se realizaron preparados permanentes en los cuales se contaron hasta 300 valvas. Se utilizó como medio dispersante Cumar (IR: 1.72).

La observación de las diatomeas se realizó en un microscopio óptico Olympus, con aumento de x1500 y se tomaron microfotografías con cámara Olympus SC 35, para clasificación de las mismas se consultaron los trabajos de Simonsen (1979), Hustedt (1957), Patrick \& Reimer (1966, 1975), Hendey (1964), Luchini \& Verona (1972), Germain (1981), Ricard (1987) y Krammer \& Lange-Bertalot (1986, 1991a,b, 1988). Se siguió el sistema de clasificación de Round et al. (1990) y las tipologías de cada especie fueron
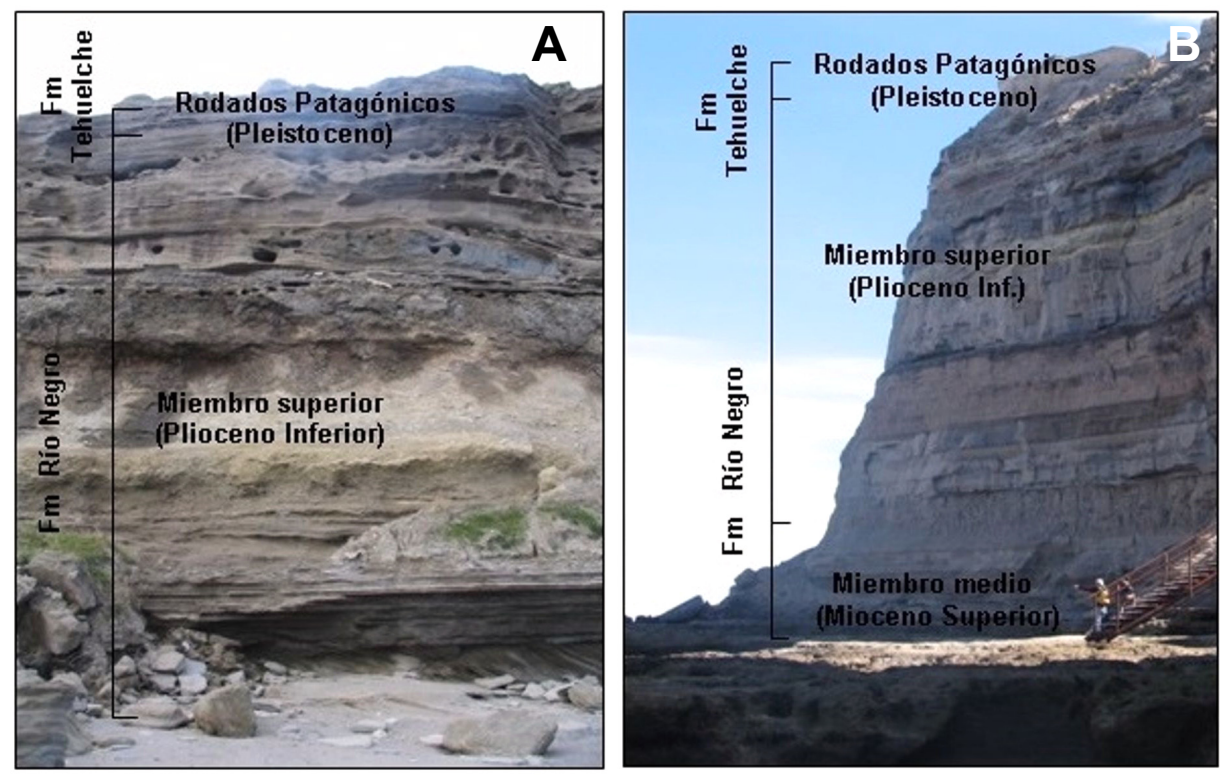

Figura 2. A, perfil El Faro; B, perfil El Espigón.

Figure 2. A, El Faro profile; B, El Espigón profile. 

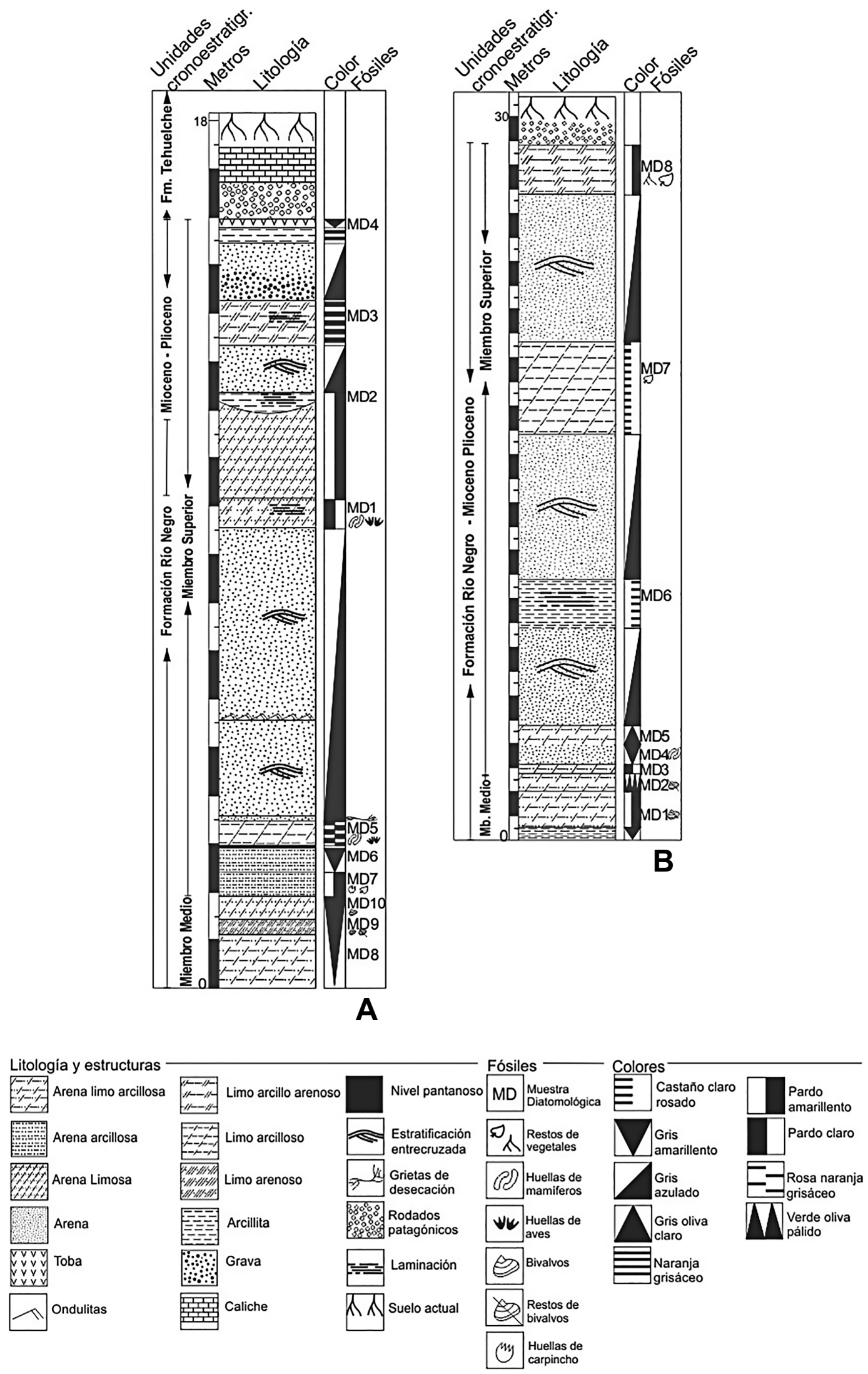

Figura 3. A, perfil estratigráfico El Faro; B, perfil estratigráfico El Espigón.

Figure 3. A, El Faro stratigraphic profile; B, El Espigón stratigraphic profile. 


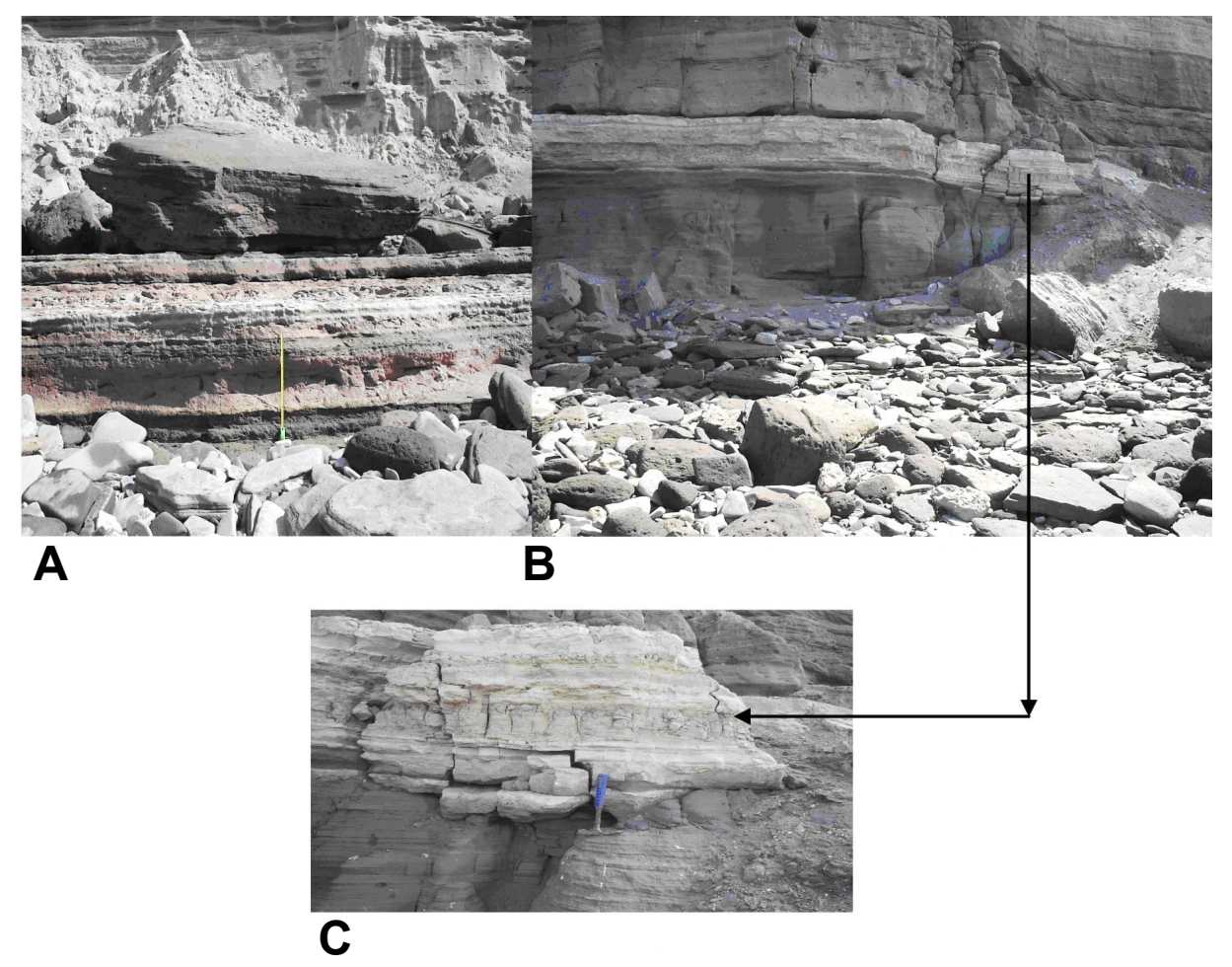

Figure 4. A, sección sedimentaria I (SS I); B, sección sedimentaria II (SS II); C, detalle de la sección sedimentaria muestreada.

Figure 4. A, sedimentary section I (SS I); B, sedimentary section II (SS II); C, detail of the studied sedimentary section.

actualizadas utilizando los nombres aceptados por Algaebase (Guiry \& Guiry, 2009). Las características ecológicas de las especies fueron tomadas de De Wolf (1982), Denys (1991) y Vos \& De Wolf $(1988,1993)$ con el objeto de relacionar los taxones hallados con las distintas variables ambientales. Los resultados obtenidos se graficaron en diagramas de frecuencias relativas utilizando el programa TILIA(Grimm, 2004). Sobre los mismos preparados diatomológicos se realizó el estudio de los cistos de crisostomatáceas (Clase Chrysophyceae), cuyos morfotipos fueron identificados siguiendo a Sandgren (1991), Vigna (1995) y Coradeghini \& Vigna (2001). Se analizó la frecuencia relativa de los estomatocistos con relación a la frecuencia de frústulos de diatomeas (Battarbee et al., 2001).

\section{RESULTADOS}

La reconstrucción de los ambientes se basó en las características autoecológicas y frecuencias relativas de los taxones de diatomeas hallados. El perfil El Faro permitió diferenciar el Miembro superior y medio de la Formación Río Negro (Figuras 2A, 3A). El primer estrato de 17,5 m de espesor se inicia (techo): (a) con un suelo actual con rodados poco cementado por calcáreos; (b) toba gris clara poco consolidada con abundante cuarzo; (c) arcilita parda, laminada con intercalaciones de gravas arenosas y óxidos de hierro. Presenta abundantes frústulos de diatomeas, espículas de esponjas y vegetales oxidados; (d) arenisca gris-azulada con estratificación entrecruzada e intercalación lentiforme de arcilla; (e) arenisca limosa pardo azulada, con estratificación horizontal que en parte se torna masiva. Presenta abundantes frústulos de diatomeas, nódulos de $\mathrm{CaCO}_{3}$ y huellas de aves y mamíferos (Aramayo, 2007, 2008); (f) areniscas limoarcillosas, con estratificación entrecruzada, ondulitas, grietas de desecación y abundantes nódulos de Fe. Acompañan frústulos de diatomeas, vegetales oxidados y huellas de mamíferos. La base (g) finaliza con arenisca gris clara, cementada por carbonato de calcio, con intercalaciones arcillosas. Presenta frústulos de diatomeas, estomatocistos de Chrysophytas, espículas de esponjas, nódulos de hierro y huellas de carpincho (Rodentia, Caviomorpha). El ensamble diatomológico está dominado por Cyclotella ocellata Pantocsek y Aulacoseira granulata (Ehr.) Simonsen, diatomeas de ambientes salobres a dulceacuícolas. El Miembro medio, de 1,30 m de espesor, presenta limolita arenosa parda oscura con intercalaciones de conchillas de bivalvos, junto con Paralia sulcata (Ehr.) Cleve y Coscinodiscus lineolatus Ehrenberg, diatomeas de ambiente marino/costero (Figura 6).

El perfil El Espigón también presenta estratos del Miembro superior y medio de la Formación Río Negro (Figuras 2B, 3B). El primero de ellos de 26,50 $\mathrm{m}$ de potencia, presenta en el techo (a) un nivel de rodados sueltos; (b) arcilita limosa algo arenosa, nódulos arcillo-yesosos, con óxidos de Fe y trizas volcánicas. Acompañan restos de raices momificadas y frústulos de diatomeas; (c) arenisca gris azulada, con estratificación entrecruzada. Intercala una arcilita parda, finamente laminada con frústulos de diatomeas; (d) arenisca gris azulada con estratificación entrecruzada; (e) arcilita compacta con fina laminacion 


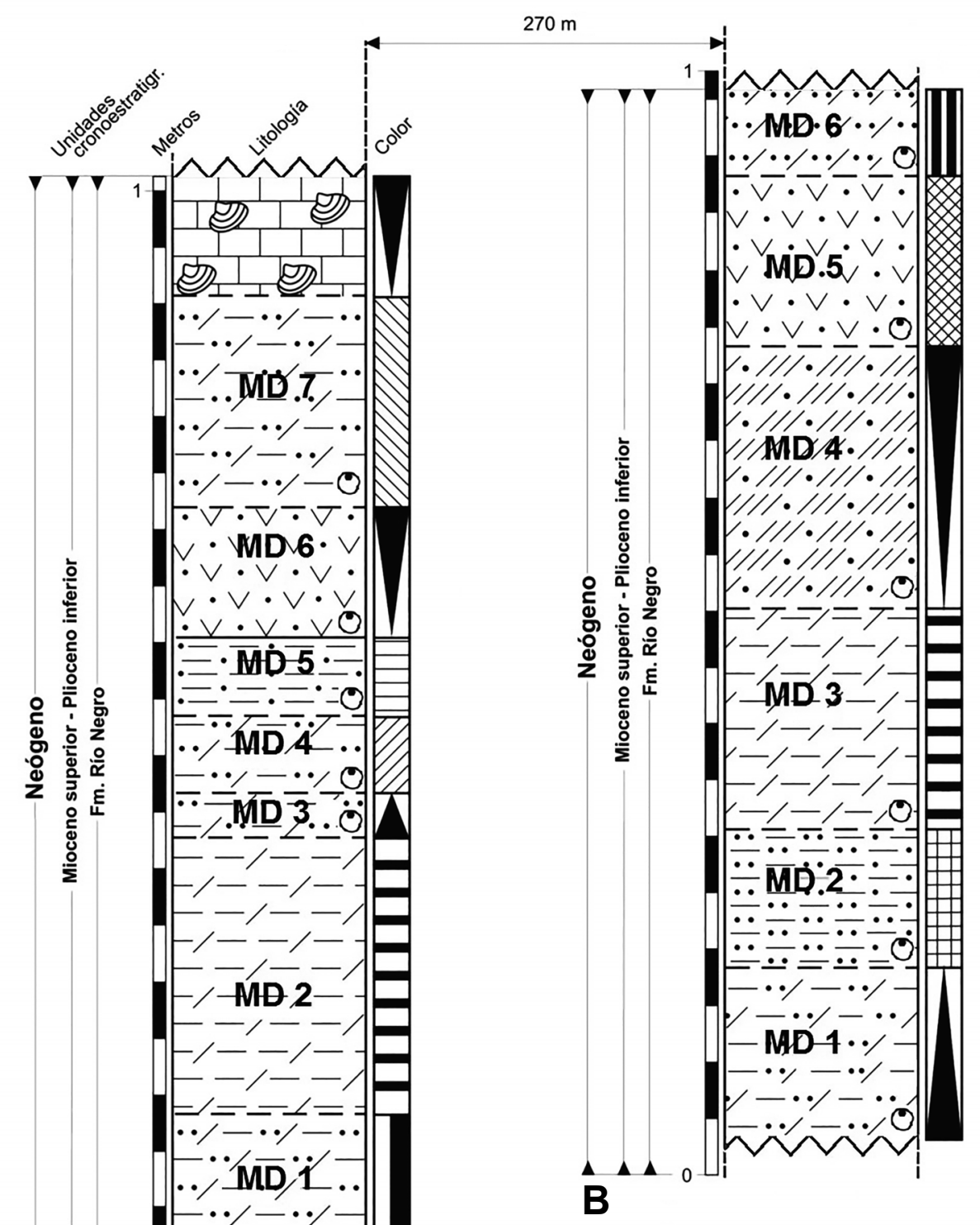

Fósiles

Cistos de crysophytas Moldes de bivalvos MD Muestra diatomológica

\begin{tabular}{|c|c|c|c|}
\hline 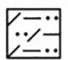 & Arena limo-arcillosa & Pיתו & Limo arenoso \\
\hline $\begin{array}{ll:}\ddot{*} * \\
\ddot{*}\end{array}$ & Arena arcillosa & 忈: & Arcilla arenosa \\
\hline ए๐: & Arena limosa & $\because \dot{v}$ & Toba \\
\hline E八 & Limo arcilloso & & Caliza \\
\hline & Contacto transiciona & 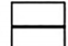 & Contacto neto \\
\hline
\end{tabular}

\begin{tabular}{|c|c|c|}
\hline & Amarillento moderado & Gris oliva claro \\
\hline & Rosa grisáceo & Gris mediano \\
\hline & Rosa amarillento grisáceo & Naranja pálido \\
\hline$\infty$ & Gris muy claro & Naranja grisáceo \\
\hline & Gris amarillento & Pardo amarillento \\
\hline
\end{tabular}

Figura 5. A, perfil estratigráfico de la sección sedimentaria I (SS I); B, perfil estratigráfico de la sección sedimentaria II (SS II).

Figure 5. A, stratigraphic profile of the sedimentary section I (SS I); B, stratigraphic profile of the sedimentary section II (SS II). 


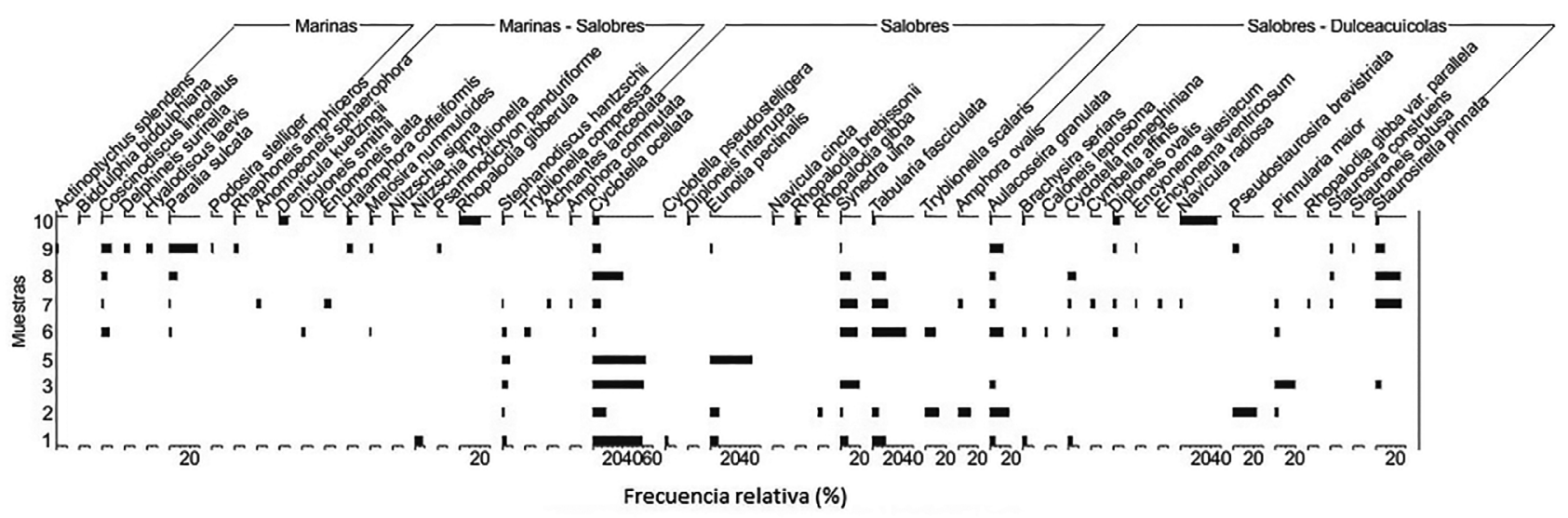

Figura 6. Diagrama de diatomeas del perfil El Faro.

Figure 6. Diatom diagram from El Faro profile.

horizontal y frústulos de diatomeas; (f) arenisca gris azulada con estratificación entrecruzada; (g) arcilita limosa con menor proporción de areniscas, aglutinados arcilloyesosos, trizas volcánicas y materia orgánica; (h) areniscas limoarcillosas, con aglomerados arcillosos, trizas volcánicas, espículas de esponjas, frústulos de diatomeas y huellas de mamíferos; (i) arcilita limosa y arena en proporciones similares, con frústulos de diatomeas; (j) arenisca limoarcillosa, con trizas volcánicas, frústulos de diatomeas, fragmentos de bivalvos y ostrácodos. La base con (k) arcilita gris amarillenta moderadamente consolidada. El ensamble diatomológico del Miembro superior está dominado por Cyclotella ocellata, Staurosirella pinnata (Ehr.) Williams et Round y Cocconeis placentula Ehrenberg de ambientes salobres a dulceacuícolas y con menor frecuencia Tabularia fasciculata (Agardh) Williams et Round, de ambientes salobres con marcada evaporación. El Miembro medio, de 2,50 $\mathrm{m}$ de espesor, esta dominado por arcilitas y limolitas arenosas pardo y gris amarillentas, con fragmentos de valvas de bivalvos fuertemente desgastadas. Este Miembro resultó estéril en diatomeas (Figura 7).

Se realizó el estudio diatomológico de dos secciones sedimentarias (SS I y SS II) (Figuras 4, 5). La SS I está compuesta por techo: (a) arenisca limoarcillosa, con trizas volcánicas, espículas de esponjas, restos de vegetales oxidados y frústulos de diatomeas y base; (b) toba con material piroclástico fino, trizas volcánicas y frústulos de diatomeas. El ensamble de diatomeas está dominado por Staurosirella pinnata, Cyclotella ocellata, Aulacoseira granulata, características de ambientes salobres a dulceacuícolas, y Halamphora veneta (Kützing) Levkov, en los niveles de toba (Figura 8). La SS II está constituída por techo: (a) arenisca arcillosa hasta limosa, trizas volcánicas, vegetales oxidados, espículas de esponjas, estomatocistos de Chrysophytas y frústulos de diatomeas y base; (b) toba con material piroclástico blanco grisáceo, laminación horizontal, teñida por óxidos de hierro, restos de vegetales oxidados, cistos de Crisófitas y frústulos de diatomeas. El ensamble diatomológico está dominado por Aulacoseira granulata,
Halamphora veneta, Cyclotella ocellata y Staurosirella pinnata, de ambientes dulceacuícolas (Figura 9).

\section{DISCUSIÓN}

En el perfil El Faro, los estratos inferiores del Miembro Superior de la Formación Río Negro, corresponderían a cuerpos lagunares de interduna, con depositación laminar de los sedimentos y un nivel de agua profundo, indicado por la presencia de diatomeas oligohalobias halófilas, planctónicas como Cyclotella ocellata y Aulacoseira granulata. Las grietas de desecación señalarían la exposición aérea del nivel lagunar, en cuyos bordes quedan marcadas icnitas de aves y mamíferos en búsqueda de agua y alimento (Aramayo, 2007). La presencia de Tabularia fasciculata, epífitabentónica indicaría un aumento en la salinidad debido a una mayor evaporación y aridización del clima. En los estratos superiores, la presencia de Cyclotella ocellata sería una evidencia de cuerpos lagunares de interduna con depositación laminar de los sedimentos y cercanía del borde litoral, con la interrupción de un nivel de toba volcánica acumulada en un breve espacio de tiempo y estéril en diatomeas. En el Miembro Medio de la Formación Río Negro la observación de valvas de ostreidos en el techo del estrato, junto con la presencia de diatomeas alóctonas de origen marino costero como Paralia sulcata, señalaría un flujo de agua de mar que inundó de manera temporal el área. Este taxón es uno de los más utilizados en reconstrucciones paleoambientales de ambientes costeros, ya que es muy abundante en los sedimentos, se encuentra ampliamente distribuido y es muy resistente a la disolución (Mc Quoid \& Nordberg, 2003). La manifestación de Cyclotella ocellata indica los inicios de la formación de una laguna de interduna en el piso del estrato. La acumulación observada en el Miembro Medio, está relacionada con medios marinos someros afectados por oleajes, los que dieron origen a concentraciones de bivalvos ostreidos en forma de bolsones (Farinati \& Zavala, 2005).

En el perfil El Espigón los niveles estériles en diatomeas junto con la observación de valvas rotas estarían relacionadas 


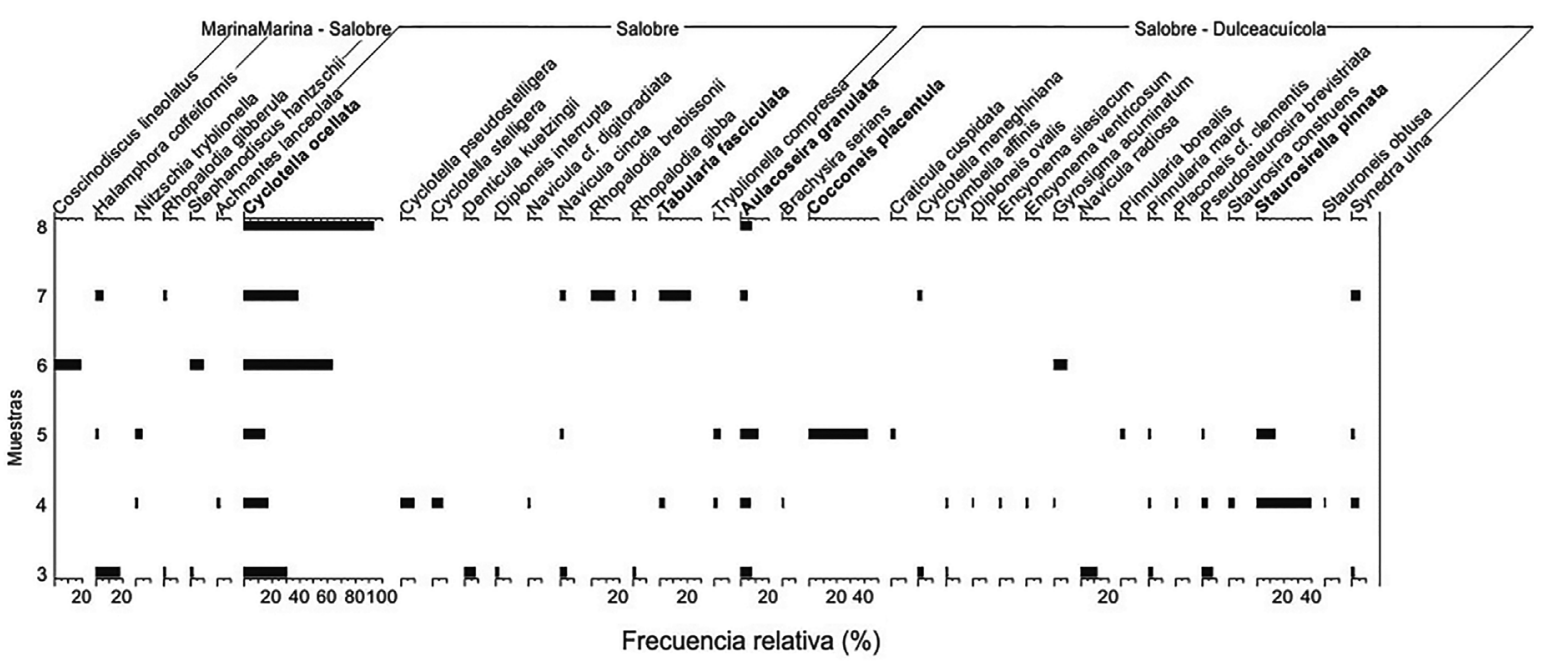

Figura 7. Diagrama de diatomeas del perfil El Espigón.

Figure 7. Diatom diagram from El Espigón profile.

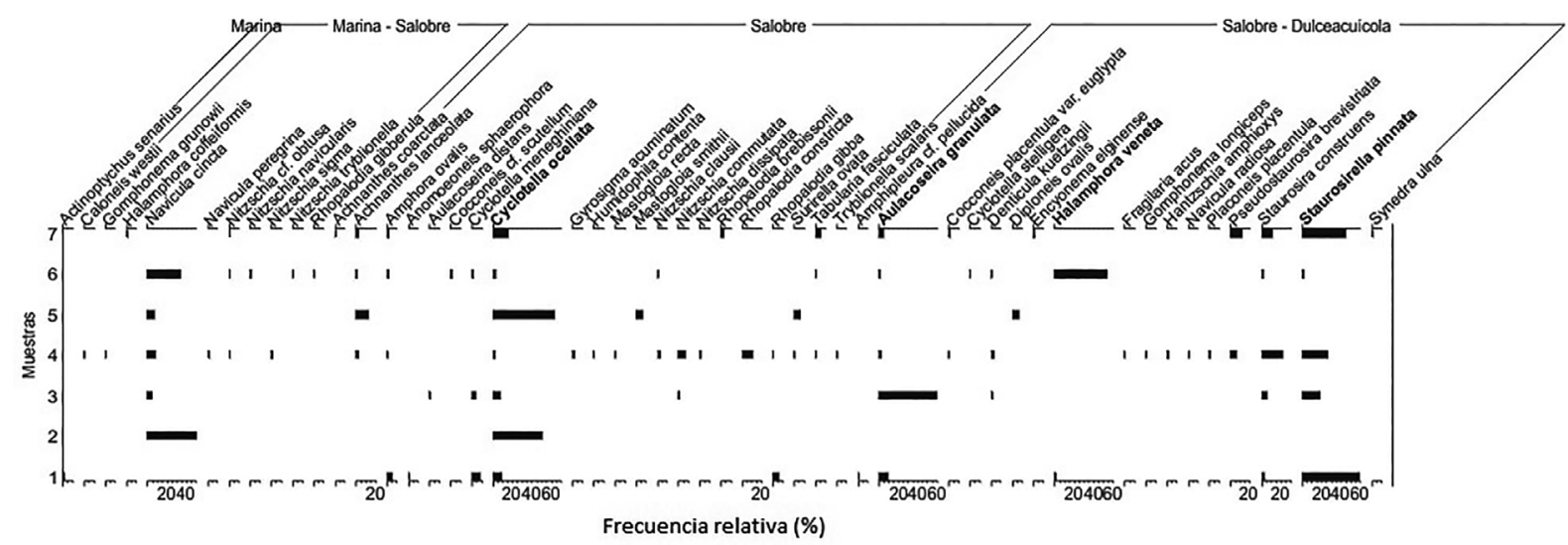

Figura 8. Diagrama de diatomeas de la sección sedimentaria I.

Figure 8. Diatom diagram of the sedimentary section I.

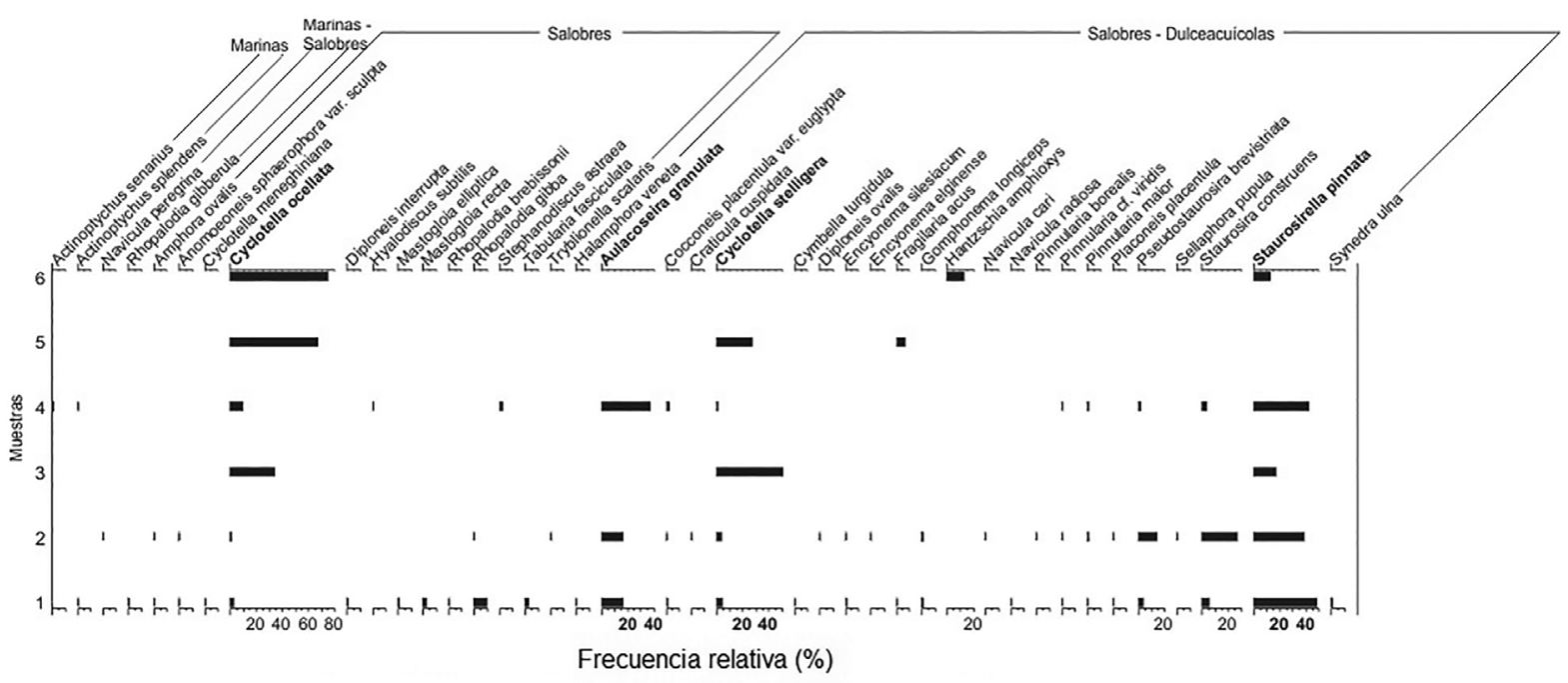

Figura 9. Diagrama de diatomeas de la sección sedimentaria II.

Figure 9. Diatom diagram of the sedimentary section II. 
con un momento de ingresión y regresión abrupta del mar (Farinati, 2007). Los depósitos originados en un ascenso inicial en el nivel del mar se caracterizan por la riqueza en moluscos bivalvos, con un momento de máxima inundación y sedimentación mínima, la que queda evidenciada por la ausencia de diatomeas en los estratos. Posteriormente cambios en el nivel relativo del mar producen una rápida somerización, que culmina con una desecación y posterior depositación del Miembro Superior eólico de la Formación Río Negro (Zavala \& Freije, 2001). La presencia de Cyclotella ocellata junto con bivalvos y ostrácodos, indicaría un ambiente de agua salobre a dulce con influencia eólica, de tipo arenosa. La manifestación de Staurosirella spp. y Cocconeis placentula, bentónicas y epífitas, denotarían un cuerpo de agua lagunar con cercanía del borde litoral, con depositación rítmica de los sedimentos. Las grietas de desecación observadas en la base y techo de los estratos, determinarían los límites del cuerpo de agua, alrededor del cual dejaron sus huellas aves y mamíferos. Por otra parte, la estructura laminar de los materiales arcillosos señalaría la presencia de cuerpos lagunares de poca profundidad. Se infiere un ambiente de interdunas con influencia eólica y ácuea por escurrimiento, con exposición aérea indicada por restos vegetales oxidados, los que marcarían la cercana continentalización del ambiente.

Los sedimentos arenosos del Miembro Superior de la Formación Río Negro, impidieron la retención de frústulos; la aridización, la evaporación y los niveles de agua de las lagunas intermedanosas fueron lo suficientemente bajos y secos, para impedir un aumento en la diversidad de especies de agua dulce y favorecer el incremento de diatomeas de agua salobre. El Miembro Medio, correspondiente al Miembro marino, coincide con una influencia marginal episódica del mar, indicada por la aparición de escasas diatomeas polihalobias, características de ambientes marinos costeros.

Los paleoambientes determinados en los perfiles El Faro y El Espigón, habrían estado expuestos a una alternancia entre períodos secos y húmedos. El estudio diatomológico de las SS I y II, permitió inferir que las mismas corresponderían a cuerpos lagunares intermedanosos. Estos ambientes, si bien son medios geológicos restringidos, poseen gran susceptibilidad frente a las variaciones climáticas. Son indicadores de gran importancia en la determinación y evolución de los cambios que un ambiente ha soportado, ya que sus características sedimentológicas se conservan en el tiempo, lo que permite su estudio luego de que los cuerpos de agua han desaparecido (Dangavs, 2005; Schillizzi \& Luna, 2008). La formación de paleocanales de sedimentos finos estaría relacionada con escorrentías vinculadas a precipitaciones intensas y estacionales, que habrían generado cuerpos de agua someros. El relleno de los paleocanales con sedimentos loéssicos se debería a material que habría decantado de los ambientes lagunares y representaría intervalos secos, sin precipitaciones importantes (Pérez et al., 2013). La SS I habría reducido su caudal por evaporación en respuesta a un aumento de la aridez, manifestado por la presencia de Staurosirella pinnata, oligohalobia indiferente, bentónica a ticoplanctónica y Halamphora veneta, oligohalobia indiferente a oligohalobia halófila, bentónica y epífita, diatomeas características de cuerpos de agua salobres a dulces y poco profundos. La presencia de Halamphora veneta es indicadora de una depositación rápida como consecuencia de la acumulación de ceniza volcánica. Luego del evento de aridización, se habría incrementado el aporte hídrico proveniente de la conjunción de procesos como aumento de lluvias y contribución de canales fluviales, permitiendo el desarrollo de Cyclotella ocellata y Aulacoseira granulata, planctónicas y ticoplanctónicas, propias de niveles de agua profundos. En el techo de esta geoforma se destaca la colonización de una fauna fósil de bivalvos endobentónicos, dulceacuícolas (Diplodon sp.), típicos de ambientes lagunares (Schillizzi \& Luna, 2008). En ésta sección se identificaron un total de seis morfotipos de cistos (Coradeghini \& Vigna, 2001) los cuales no superan al de frústulos de diatomeas, lo que indicaría condiciones favorables para el desarrollo de las mismas.

En la SS II dominan taxones como Staurosirella pinnata en forma alternante con Cyclotella ocellata. La diversidad encontrada en este paleoambiente decrece de manera lineal desde la base hacia el techo del perfil. En esta sección la alternancia entre períodos húmedos y secos es menos marcada, ya que presenta una variación muy leve en sus niveles de salinidad, lo cual se correspondería con una mayor estacionalidad climática, debida al poco aporte de agua meteórica y a temperaturas menos elevadas. Por lo tanto, en ambas geoformas se observa una sucesión diatomológica, siendo Staurosirella pinnata y Halamphora veneta especies

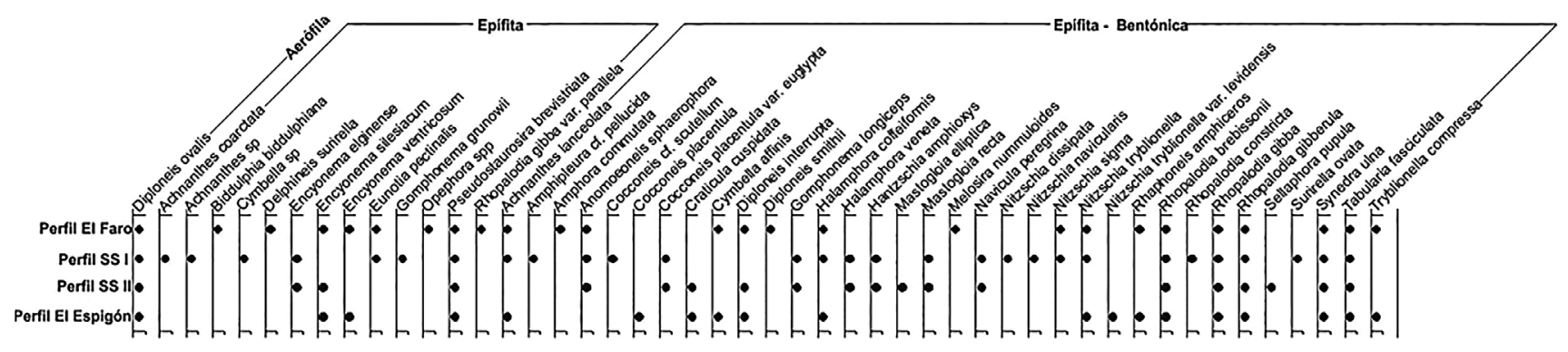

Figura 10. Diagrama del total de taxones identificados según su forma de vida (parte 1).

Figure 10. Diagram of all taxa identified according to lifestyle (part 1). 


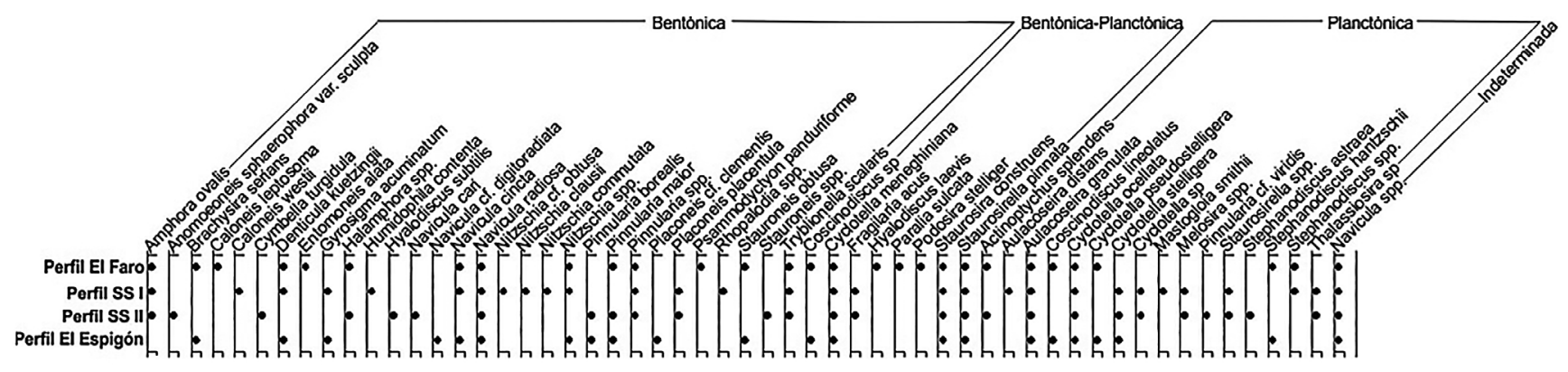

Figura 11. Diagrama del total de taxones identificados según su forma de vida (parte 2).

Figure 11. Diagram of all taxa identified according to lifestyle (part 2).

dominantes en períodos secos con mayor evaporación del cuerpo de agua y Cyclotella ocellata junto con Aulacoseira granulata dominantes en períodos húmedos.

En la SS II la disminución de la diversidad de frústulos se opone a un aumento considerable en el número de cistos, éste incremento representaría una disminución en la concentración de nutrientes del cuerpo de agua. Se observa luego, un crecimiento considerable en el número de cistos superando al número de frústulos. Este aumento progresivo denotaría un deterioro en el ambiente, el cual se tornaría inadecuado para el desarrollo de las diatomeas.

\section{CONCLUSIONES}

Del análisis de los sedimentos de perfiles ubicados en la costa norte del Golfo San Matías, surge un registro de 104 taxones de diatomeas discriminados en 20 correspondientes al Orden Centrales y 84 al Orden Pennales (Figuras 10, 11).

El estudio de los ensambles permitió diferenciar diatomeas bentónicas de planctónicas y con ellas establecer una mayor o menor profundidad en los cuerpos de agua continentales y marinos. En el perfil El Faro, la presencia de Cyclotella ocellata en los estratos inferiores del Miembro Superior, indicaría cuerpos lagunares de interduna, la manifestación de Staurosirella spp., confirmarían la amplitud del borde litoral, mientras que las grietas de desecación señalarían la exposición aérea de los cuerpos lagunares. En el Miembro Medio la presencia de diatomeas alóctonas de origen marino como Paralia sulcata, Actinoptychus splendens (Shadb) Ralfs, Biddulphia biddulphiana (J. Smith) Boyer y Coscinodiscus lineolatus, señalarían un flujo de agua de mar que habría inundado de manera temporal el área.

En el perfil El Espigón los niveles estériles en diatomeas, debido a una sedimentación mínima, junto con la observación de valvas rotas de moluscos determinarían un momento de máxima inundación y otro de regresión abrupta del mar. Cyclotella ocellata y Aulacoseira granulata, entre otras, indicarían un ambiente con influencia de agua salobre a dulce. La existencia de Staurosirella spp. y Cocconeis placentula, la depositación rítmica de los sedimentos, las grietas de desecación y las huellas aves y mamíferos, determinarían la presencia de un cuerpo de agua lagunar con bordes litorales marcados. Se infiere un ambiente de dunas con influencia eólica y ácuea por escurrimiento, además una posible exposición aérea por la presencia de restos vegetales oxidados, los que marcarían la cercana continentalización del ambiente.

En el Miembro Superior del perfil El Faro, los estratos inferiores corresponderían a cuerpos lagunares de interduna, con diferentes ensambles diatomológicos que brindarían información sobre los períodos húmedos y secos que debió soportar el ambiente y que modificaron la salinidad de los cuerpos de agua. La presencia de Staurosirella pinnata y Halamphora veneta indicaría un cuerpo de agua pando, vegetado y con cercanía al borde litoral. Cyclotella ocellata y Aulacoseira granulata, confirmarían que las lagunas habrían sido de agua salobre a dulce y de mayor caudal.

En la SS I se observa una alternancia entre períodos secos y húmedos, en los primeros la laguna habría reducido su caudal de agua por evaporación, favoreciendo la aparición de Staurosirella pinnata, luego el aporte hídrico proveniente de la conjunción de procesos como aumento de lluvias, ascenso del nivel freático y aporte de canales fluviales, habría favorecido el florecimiento de Cyclotella ocellata y Aulacoseira granulata. La fauna fósil de bivalvos endobentónicos reafirmaría el desarrollo de una nueva paleolaguna. La SS II exhibe la misma alternancia entre períodos secos y húmedos, aunque en forma menos marcada ya que presenta una variación muy leve en sus niveles de salinidad, lo que pudo deberse a una mayor estacionalidad climática. En este caso se trata de un cuerpo de agua pando, como lo indica Staurosirella pinnata, con una posterior aparición de Cyclotella ocellata que señalaría un leve aumento en el nivel de agua.

Tanto en los perfiles El Faro y El Espigón como en las SS I y II, los cistos de crisófitas habrían permitido determinar el empobrecimiento del ambiente, señalando el inicio de la desaparición de las lagunas por reducción de los aportes hídricos, aumento de evaporación al acentuarse la aridez y depositación de materiales arenosos por efecto del viento.

\section{AGRADECIMIENTOS}

Los autores desean expresar su agradecimiento al R. Schillizzi y a la D. Olivera por la revisión crítica del manuscrito. A la R. Silveira de la Universidade Federal do Amazonas por su colaboración. 


\section{REFERENCIAS}

Andreis, R.R. 1965. Petrografía y paleocorrientes de la Formación Río Negro (tramo General Conesa- Boca del Río Negro). Revista del Museo de La Plata, 36:245-310.

Angulo, R.J \& Casamiquela, R.M. 1982. Estudio estratigráfico de las unidades aflorantes en los acantilados de costa norte del Golfo San Matías (Río Negro y extremo austral de Buenos Aires) entre los meridianos 62 $2^{\circ} 30^{\prime}$ y 6430'. Mundo Ameghiniano, 2:20-73.

Aramayo, S.A. 1987. Plohoporus aff figuratus (Edentata Glyptodontidoe) en la Formación Río Negro (Mioceno tardíoPlioceno), Provincia de Río Negro, Argentina. Importancia bioestratigráfica. In: CONGRESO GEOLÓGICO ARGENTINO, 10, 1987. Actas, San Miguel de Tucumán, p. 171-174.

Aramayo, S.A. 1999. Nuevo registro de icnitas en la Formación Río Negro (Mioceno tardío-Plioceno temprano) Provincia de Río Negro, Argentina. Ameghiniana, 36:5R-6R.

Aramayo, S.A. 2007. Neogene Vertébrate Palaeoichnology of the North Atlantic coast of Rio Negro Province, Argentina. Arquivos do Museu Nacional, 65:573-584.

Aramayo, S.A. 2008. Phorusrhacidae footprins at the Río Negro Formation (Late Miocene-early Pliocene) Atlantis coast of Rio Negro province, Argentina. In: INTERNATIONAL CONGRESS OF ICHNNOLOGY, 2, 2008. Abstracts, Kraków, p. 12-13.

Aramayo, S.A.; Barros, M.; Candel, S.Y.; Vecchi, L. 2004. Mammal and bird footprints at Río Negro Formation (Late Miocene-early Pliocene), Rio Negro Province, Argentina. In: INTERNATIONAL CONGRESS ON ICHNOLOGY, 1, 2004. Abstracts, Trelew, p. 14.

Battarbee, R.W. 1986. Diatom analysis. In: B.E. Berglund (ed.) Handbook of Holocene paleoecology and paleohydrology, Wiley \& Sons, p. 527-570.

Battarbee, R.W.; Jones, V.J.; Flower, R.J., Cameron, N.G.; Bennion, H.; Carbalho, L. \& Juggins, S. 2001. Diatoms. In: J.P. Smol; H.J.B. Birks \& W.M. Last (eds.) Tracking environmental change using lake sediments, Kluwer Academic Publishers, p. 155-202.

Coradeghini, A. \& Vigna, M.S. 2001. Flora de quistes crisofíceos fósiles en sedimentos recientes de Mallín Book, Río Negro (Argentina). Revista Española de Micropaleontología, 33:163-181.

Dangavs, N. 2005. Los ambientes acuáticos de la Provincia de Buenos Aires. En: Geología y Recursos Minerales de la Provincia de Buenos Aires. In: CONGRESO GEOLÓGICO ARGENTINO, 16, 2005. Relatorio, La Plata, p. 219-236.

De Wolf, H. 1982. Method of coding of ecological data from diatoms for computer utilization. Geological Survey of Netherlands, 36:95-98.

Del Río, C.J. \& Martínez, S. 1998. El Mioceno marino en la Argentina y en el Uruguay. In: C.J. Del Río (ed.) Moluscos marinos Miocenos de la Argentina y del Uruguay, Buenos Aires, Academía Nacional Ciencias Exactas, Físicas y Naturales de Buenos Aires, p. 5-25 (Monografías 15).

Denys, L. 1991. A check-list of the diatoms in the Holocene deposits of the Western Belgian coastal plain with the survey of their apparent ecological requirements. I. Introduction, ecological code and complete list. Brussels, Geological Survey of Belgium, 92 p. (Professional Paper 247).

Dias, J.L.; Sad, A.R.E.; Fontana, R.L. \& Feijóp, F.J. 1994. Bacia de Pelotas. Boletim de Geociencias da Petrobras, 8:235-245.

Domenech, R. \& Farinati, E.A. 2007. Análisis tafonómico de concentraciones de ostras (Ostrea patagonica) en el Mioceno de Patagonia Argentina. Cuaderno del Museo Geominero, 8:117- 122 .
Escandell, A.; Espinosa, M. \& Isla, F. 2009. Diatomeas como indicadoras de variaciones de salinidad durante el Holoceno tardío en el río Negro, Patagonia Norte, Argentina. Ameghiniana, 46:1-8.

Farinati, E.A. 2007. Trace fossils in firm sediment and skeletal subtrates, Miocene to Pliocene, Patagonia, Argentina. In: R.G. Bromley; L.A. Buatois; G. Mángano; J.F. Genise \& R.N. Melchor (eds.) Sediment-organism interactions: multifaceted ichnology, Tulsa, Society for sedimentary Geology, p. 279-285 (Special Publications 88).

Farinati, E.; Fernández, A.L.; Higuera-Ruiz, R.; Ibisate, R. \& Elorza, J. 2010. Respuesta morfológica y microestructural condicionada por estrés en Crassostrea patagonica (D'Orgigny) de la Formación Río Negro (Mio-Plioceno), Patagonia, Argentina. Revista de la Sociedad Geológica de España, 23:9-22

Farinati, E.A. \& Zavala, C. 2005. Asociaciones de megafósiles de invertebrados en el Neógeno Atlántico de la Patagonia Argentina. Revista de la Sociedad Geológica de España, 18:187-194.

Fayó, R \& Espinosa, M. 2014. Reconstrucción paleoambiental de la planicie costera de Mar Chiquita (Provincia de Buenos Aires, Argentina) durante el Holoceno, basada en diatomeas. Ameghiniana, 51:510-528. doi:10.5710/AMGH.13.10.2014.2812

Frenguelli, J. 1939a. Diatomeas de Rada Tilly en el Golfo de San Jorge (Chubut). Revista del Museo de La Plata II, 2:179-199.

Frenguelli, J. 1939b. Diatomeas del Golfo San Matías (Río Negro). Revista del Museo de La Plata II, 2:201-231.

Germain, H. 1981. Flore des Diatomées Diatomophycées eaux douces et saumatres du Massif Armoricain et des contrées voisins d'Europe Occidentale. Paris, Societé Nouvelle des Editions Boubée, $444 \mathrm{p}$.

Goso, H. \& Bossi, J.C. 1966. Cenozoico. In: J.C. Bossi (ed.) Geologia del Uruguay, Universidad de la República, p. 259-305.

Grimm, E.C. 2004. TGVIEW 2.0.2 (Computer Software). Illinois State Museum, Research and Collections Center, Springfield, Il.

Guiry, M.D. \& Guiry, G. M. 2009. Algaebase. National University of Ireland. Avaliable at http://www.algaebase.org; accessed on 07/12/2015.

Gutiérrez Téllez, B. 2007. Reconstrucción paleoambiental del cuaternario de la cuenca del arroyo Napostá Grande, provincia de Buenos Aires. Universidad Nacional del Sur, Ph.D. Thesis, 165 p.

Hendey, I.N. 1964. An introductory account of the smaller algae of British Coastal waters. part. V. Bacillariophyceae (Diatoms). London, Fishery Investigations Service, Her Majesty's stationery office, 317 p. (Series 4).

Hustedt, F. 1957. Die Diatomeenflora des Fluss-sistems der Weser im Gebiet der Hansestadt Bremen. Abhandlunzen herausgegeben von Naturwissenchaftichen Verein zu Breme, 34:181-440.

Krammer, K. \& Lange-Bertalot, H. 1986. Bacillariophyceae Teil: 1. Naviculaceae. In: H. Ettl; J. Gerloff; H. Heynig \& D. Mollenhauer (eds.) Süsswasserflora von Mitteleuropa. Band 2/1. Gustav Fisher, 876 p.

Krammer, K. \& Lange-Bertalot, H. 1988. Bacillariophyceae Teil: 2. Bacillariophyceae, Epithemiaceae, Surirellaceae. In: H. Ettl; J. Gerloff; H. Heynig \& D. Mollenhauer (eds.) Süsswasserflora von Mitteleuropa. Band 2/2, Gustav Fisher, 596 p.

Krammer, K. \& Lange-Bertalot, H. 1991a. Bacillariophyceae Teil: 3. Centrales, Fragilariaceae, Eunotiaceae. In: H. Ettl; J. Gerloff; H. Heynig \& D. Mollenhauer (eds.) Süsswasserflora von Mitteleuropa. Band 2, Gustav Fisher, $576 \mathrm{p}$.

Krammer, K. \& Lange-Bertalot, H. 1991b. Bacillariophyceae Teil: 4. Achnanthaceae, Kristische Esrgänzungen Zu Navicula (Lineolatae) und Gomphonema. In: H. Ettl; J. Gerloff; H. Heynig \& D. Mollenhauer (eds.) Süsswasserflora von Mitteleuropa. Band 2/3, Gustav Fischer, 576 p. 
Luchini, L. \& Verona, C.A. 1972. Catálogo de las diatomeas argentinas. Diatomeas de aguas continentales (incluido el Sector Antártico). Buenos Aires, Comisión de Investigaciones Científicas de la Provincia de Buenos Aires, 304 p. (Monografía 2).

Malumian, N.; Echeverria, A.; Martinez, M.J.C. \& Nañez, C. 1984. Los microfósiles. In: CONGRESO GEOLÓGICO ARGENTINO, 9, 1984. Relatorio, Bariloche, AGA, p. 485-526.

Martínez Macchiavello, J.C. 1975. Diatomeas (Bacillariophyta) fósiles de las cercanías de Colonia, República Oriental del Uruguay. In: CONGRESO ARGENTINO DE PALEONTOLOGÍA Y BIOESTRATIGRAFÍA, 1, 1975. Actas, Tucumán, APA, p. 317-328.

Marengo, H.G. 2000. Rasgos micropaleontologícos de los depósitos de la transgresión Entrerriense - Paranense en la Cuenca Chaco - Paranense y Noroeste Argentino, Republica Argentina. In: F.G. Aceñolaza \& R. Herbst (eds.) El Neógeno de Argentina, Tucumán, INSUGEO, p. 9-27 (Serie Correlación Geológica 14).

Mcquoid, M.R. \& Nordberg, K. 2003. The diatom Paralia sulcata as an environmental indicator species in coastal sediments. Estuarine, Coastal and Shelf Science, 56:339-354. doi: 10.1016/ S0272-7714(02)00187-7

Ojeda, H.A.O. 1982. Structural framework, stratigraphy, and evolution of Brazilian marginal basins. American Association of Petroleum Geologists Bulletin, 66:732-749.

Patrick, R. \& Reimer, C.W. 1966. The Diatoms of United State (Exclusive of Alaska and Hawaii): Fragilariaceae, Eunotiaceae, Achanthaceae, Naviculaceae. Philadelphia, Academy of Natural Sciences of Philadelphia, 688 p. (Monograph 13).

Patrick, R. \& Reimer, C.W. 1975. Diatoms of United State (Exclusive of Alaska and Hawaii): Entomoneidaceae, Cymbellaceae, Gomphonemaceae, Epithemiaceae. Philadelphia, Academy of Natural Sciences of Philadelphia, 213 p. (Monograph 13).

Perez, M.; Umazano, A.M. \& Visconti, G. 2013. Análisis paleoambiental del miembro superior de la Formación Río Negro (Mioceno-Plioceno de la Patagonia septentrional): un ejemplo de interacción fluvio-eólica compleja. Revista de la Sociedad Geológica de España, 26:25-39.

Ricard, M. 1987. Atlas du phytoplankton marin. Paris, Editions du Centre Nacional de la Recherche Scientifique, 297 p.

Rock-Color Chart Committee. 1980. Rock-Color Chart. Boulder, Geological Society of America.

Round, F.E.; Crawford, R.M. \& Mann, D.G. 1990. The Diatoms, biology and morphology of the genera. London, Cambridge University Press, 747 p.

Sandgren, C.D. 1991. Chrysophyte reproduction and resting cyst: a paleolimnologist's primer. Journal of Paleolimnology, 5:1-9. doi:10.1007/BF00226555

Schillizzi, R. \& Luna, L. 2008. Paleoambientes lacustres en la sección inferior de la Formación Río Negro, (Mioceno-Plioceno), Río Negro, Argentina. Geoacta, 33:11-22.

Sepulveda, E.G. \& Martinez Machiavello, J.C. 1985. La formación Puerta del Diablo (Mioceno superior - Plioceno inferior) en el gran bajo del Gualicho (Río Negro, Argentina) y su paleoecología basada en diatomeas. Ameghiniana, 22:81-96
Setty, M.G.A.P. 1966. Preparation and method of fossil diatoms. Micropaleontology, 12:511-514. doi:10.2307/1484796

Simonsen, R. 1979. The Diatom system: idea on phylogeny. Bacillaria, 2:9-71.

Smol, J.P. 1985. The radio of diatom frustules to chrysophycean statospores: a useful paleolimnological index. Hydrobiologia, 123:199-208. doi: 10.1007/BF00034378

Sprechmann, P.; Ferrando, L.A. \& Martínez, S. 2000. Estado actual de los conocimientos sobre la Formación Camacho (Mioceno medio? - superior?, Uruguay). In: F.G. Aceñolaza \& R. Herbst (eds.) El Neógeno de Argentina, Tucumán, INSUGEO, p. 47-65 (Serie Correlación Geológica 14).

Sprechmann, P.; Martínez, S. \& Gaucher, C. 1994. Paleoecologóa y sedimentología de la Formación Camacho en el Departamento de Colonia (Mioceno Medio - Superior, Uruguay). Paleociencias del Uruguay, 2:21-24.

Vigna, M.S. 1995. Flora fósil de estatósporas crisofíceas (Chrysophyta) en sedimentos recientes del lago Nahuel-Huapi (Río Negro, Argentina). Buenos Aires. Ameghiniana, 32:63-72.

Vos, P.C. \& De Wolf, H. 1988. Methodological aspects of paleoecological diatom research in coastal areas of the Netherlands. Geologie en Mijnbouw, 67:31-40.

Vos, P.C. \& De Wolf, H. 1993. Diatoms as a tool for reconstructing sedimentary environments in coastal wetlands; methodological aspects. Hydrobiologia, 269:285-296. doi: 10.1007/BF00028027

Wichmann, R. 1918. Estudios geológicos e hidrogeológicos en la región comprendida entre Boca del Río Negro, San Antonio y Choele-Choel. Buenos Aires, Ministerio de Agricultura de la Nación, Sección Geológica, Mineral y Minería, 44 p. (Anales 13).

Wichmann, R. 1919. Contribución a la geología de la región comprendida entre el Río Negro y A. Valcheta. Buenos Aires, Ministerio de Agricultura de la Nación, Sección Geología Mineral y Minería, 45 p. (Anales 13).

Zavala, C.; Abrameto, A.; Azua, G.; Freije, H., Inchentron, C.H. \& Ponce, J. 2000. Estratigrafía de los acantilados marinos de la zona de El Cóndor- Bahía Rosas (Formación Río Negro, Mioceno-Plioceno) Provincia de Río Negro. In: CONGRESO LATINOAMERICANO DE SEDIMENTOLOGÍA, 2, 2000. Resúmenes, Mar del Plata, AAS, p. 186-187.

Zavala, C. \& Freije, H. 2000. Estratigrafía secuencial del terciario superior marino de Patagonia. ¿Un equivalente de la crisis del Messiniano? Geotemas, 1:217-221.

Zavala, C. \& Freije, H. 2001. On the understanding of aeolian sequence stratigraphy: an example from Miocene-Pliocene deposits in Patagonia Argentina. Rivista Italiana di Paleontología e Stratigrafia, 107:251-264.

Zavala, C. \& Freije, H. 2005. Geología de los acantilados. En las mesetas patagónicas que caen al mar: La costa rionegrina. Río Negro, Ed. F. Masera, p. 187-197.

Received in March, 2015; accepted in November, 2015. 